study, it is concluded that this industry provides vast opportunity for further exploiting labour force in respect to production of beverage, sugar, alcohol, fibre, fuel wood, timber and row materials for handicrafts. As well as this study clearly stated that implementing innovative technologies with product diversification and opening new market channels are the necessary pre requisite of this industry in future.

\title{
010 \\ Effect of free range poultry system on land use efficiency and floral diversity in Rubber plantations
}

\author{
B M D C Balasooriya', V H L Rodrigo', S M M lqbal' and D V S de S Gamage², \\ ${ }^{1}$ Rubber Research Institute of Sri Lanka, ${ }^{2}$ Veterinary Research Institute, Sri Lanka
}

Plantation crops like rubber were traditionally grown in monocultures to avoid any risk on their productivity. However, with the smallholder farmers being involved in rubber cultivation, the idea of farming system evolved with the maximizing the overall land productivity and diversifying the income sources in order to meet the need of the resource poor. At present, rubber based intercropping systems with other economically beneficial crops are recommended and being practised to some extent particularly in smallholdings. However, no successful attempts were taken on livestock integration to the rubber system. With the understanding of practical limitations in incorporating ruminants to the system, the present study was commenced as a preliminary investigation to assess the effectiveness of free range poultry with respect to productivity and its effects on floral diversity under rubber. Based on the experience in coconut based poultry systems in Sri Lanka, a strain developed as a backcross of the hybrid between CPRS (Central Poultry Research Station) Brown and indigenous with indigenous, was used in this study expecting desired characteristics of both types. i.e., high level of egg production and adaptability to the environment. The trial began with 30 birds in a mature rubber clearing of the Rubber Research Institute of Sri Lanka. Information on egg production, the effect poultry on weed growth and its diversity were recorded together with visual observations on birds' behavior.

Average egg production was 8 eggs per bird per month. This value has dropped to 3 when the majority of birds were in moulting, However, in some months, it has gone up to 14. Some birds were killed by predators and even unsuccessful attacks affected the egg production. Birds showed poor brooding characters with that attempts taken to hatch eggs were failed. Poultry feeds had to be supplied ( $50 \mathrm{~g}$ layer ration per bird) to maintain the continuous egg production. Birds always used to feed on the area close human dwelling. Dominance of the floral species under rubber was changed with the incorporation of poultry. Although Adiantum latifolium was dominant throughout the study. Summed Dominance Ratio (SDR) of Paspalam conjugatum and Syngonium podophyllum declined with the poultry integration. Measures to be taken to improve the poultry system were also identified.

\section{1 \\ Rubber latex production in Hevea brasiliensis with high density planting \\ T U K Silva', V H L Rodrigo', S M C U P Subasinghe ${ }^{2}$ \\ 'Rubber Research Institute of Sri Lanka, \\ ¿Department of Forestry and Environmental Science, University of Sri Jayewardenepura, Sri Lanka.}

Despite short-term fluctuation of rubber prices, the demand of natural rubber has increased continuously with the increase in population and living standards of the human being. Nevertheless, urbanization results in the fast depletion of forests as well as the land area under rubber. Therefore, in order to meet the continuous demand on latex, the productivity of rubber plantations should be increased. While producing high yielding clones for improved yield per tree which is a long-term process in perennial crops, planting density could be adjusted to obtain high productivity in rubber plantations. The present level of planting density of rubber in Sri Lanka has been decided on the experiments conducted with the genotypes which are not in common use at the moment. Also, the optimum density should vary with different socio-economic conditions. Therefore, the present study was aimed to identify the suitable planting density for the recently developed and commonly used genotypes of

Proceedings of the International Forestry and Environment Symposium 2006 of the

Department of Forestry and Environmental Science. University of Sri Jayewardenepura, Sri Lanka 